\title{
Los ejercicios espirituales de Ramón del Valle-Inclán y Jorge Oteiza
}

\author{
Ignacio SÁNCHEZ SIMÓN y Eduardo MARTÍNEZ RICO
}

\section{RESUMEN}

El artículo propone una revisión del pensamiento estético de Jorge Oteiza y de Ramón del Valle-Inclán, relacionándolos ambos a través de citas de sus obras, sobre todo Goya mañana, de Oteiza, y La lámpara maravillosa, de Valle-Inclán.

Palabras clave: Oteiza, Valle-Inclán, Estética, Esoterismo, Literatura, Arte, Humanidades.

\begin{abstract}
This article is a review of the aesthetic thinking of Jorge Oteiza and Ramón del Valle-Inclán by relating them through their works, mainly Goya tomorrow, from Oteiza, and The wonderful lamp, from Valle-Inclán.
\end{abstract}

Keywords: Oteiza, Valle-Inclán, aesthetic, esoteric, literature, art, humanities.

El premio Príncipe de Asturias, Jorge Oteiza (1908-2003) no sólo fue un escultor, sino además un prolífico escritor; llegando a alcanzar alguno de sus escritos una relativa trascendencia. En sus textos se entremezclan sus teorías estéticas con otras de orden religioso, mitológico, antropológico e incluso filológico. ${ }^{1}$

Los primeros escritos los produjo durante su andadura por las principales ciudades de Sudamérica (1935-1948), adonde viajó con el firme propósito de formarse como escultor de manera autodidacta, tras el abandono de sus estudios de Medicina en Madrid.

En marzo de 1946, siendo ya profesor de cerámica de la Universidad de Cauca, en Colombia, fue invitado a pronunciar dos conferencias con motivo del segundo centenario del nacimiento de Goya. ${ }^{2}$ En ellas Oteiza, además de interpretar la obra del aragonés, aprovecha la ocasión para preconizar sus propias teorías estéticas, y

\footnotetext{
${ }^{1}$ Parte del contenido de este artículo es fruto de la Beca de investigación Itziar Carreño 2008 otorgada por la Fundación-Museo Jorge Oteiza al investigador Ignacio Sánchez Simón por su proyecto «Oteiza y los nuevos paradigmas científicos».

${ }^{2}$ A la primera fue invitado por el Centro Español de Bogotá, y a la segunda, por el Ministerio de Educación Nacional de Colombia meses después, esta vez para la clausura de la Exposición oficial de los grabados taurinos del pintor aragonés.
} 
subir así un escalón más hacia la consumación de una de sus mayores aspiraciones: ser catedrático de Estética.

En 1997, Oteiza decide rescatar aquellas conferencias y publicarlas en forma de libro. El libro, que se encuentra estructurado en ejercicios espirituales, se publicó bajo el título Goya mañana: el realismo inmóvil. ${ }^{3}$

El análisis de las numerosas concomitancias que este escrito presenta con el libro de Valle-Inclán La lámpara maravillosa: ejercicios espirituales, en el que el escritor gallego defiende su «quietismo estético», mientras ostentaba el cargo de catedrático de Estética en la Escuela de Bellas artes de Madrid, es el principal objetivo de este artículo.

Sin embargo, los paralelismos presentes en los textos de ambos escritores no se ciñen en exclusiva a estos dos libros, porque en alguna ocasión los trascienden ampliamente. De hecho, en el caso de Valle, alcanzan también a algún que otro libro de su etapa y, en el caso del escultor, a casi la totalidad de su obra escrita. ${ }^{4}$ De ahí que el objetivo del presente artículo no se circunscriba exclusivamente a esos dos libros.

\section{Esperpento y disparate}

Nada más empezar el primer ejercicio espiritual con el que Oteiza abre su Goya mañana, nos topamos de lleno con uno de los paralelismos más evidentes entre su obra y la de Valle. Allí el escultor desarrolla toda una teoría del «disparate» que en nada desmerece a la del esperpento de Valle.

Concretamente para Oteiza el disparate tiene su lógica particular en que «se basa típicamente en la dislocación formal o quebrantamiento definido de cada una de las unidades naturales». ${ }^{5}$ Mientras que para Valle la lógica de su Esperpento participa de aquella «lógica espiritual de las acciones [que] quebrantaba la lógica de los cuerpos». ${ }^{6}$

Para Oteiza el disparate es la base sobre la que se asienta su construcción estética; pero esta primera piedra no fue colocada por él. De hecho, tanto para Oteiza como para Valle aquéllos que colocaron la piedra angular de sus parejos edificios estéticos tienen nombres y apellidos. Mientras para Oteiza el primer

${ }^{3}$ En realidad los avatares editoriales de este libro son aún más enrevesados, pues en un principio iba a ser la segunda parte de otro «libro - con el título general de El Realismo Inmóvil-, que eran tres libros llenos de unidad». Pero del que sólo se publicaron los dos primeros: el primero bajo el titulo Interpretación estética de la estatuaria megalítica americana en 1952, y el segundo, el ya mencionado Goya mañana, con la inclusión de un texto conclusivo sobre el Guernica de Picasso.

${ }^{4} \mathrm{Y}$ en especial a sus Ejercicios espirituales en un túnel, auténtica continuación de los ejercicios comenzados en su Goya Mañana.

5 J. Oteiza (1997), p. 18.

${ }^{6}$ R. del Valle-Inclán (1960), p.126. 
disparate se lo debemos al Greco: «los disparates de Goya [son] sucesores inmediatos de los disparates de la vejez del Greco» $;{ }^{7}$ para Valle se lo debemos a Goya: «El esperpentismo lo ha inventado Goya». ${ }^{8}$

\section{El espejo y la cinta de Möbius}

Según ambos el punto de apoyo que les permite levantar sus respectivos aparatos estéticos tiene propiedades distorsionantes, como las que siempre presenta todo espejo, pues siempre nos devuelve nuestra imagen invertida, como si volviera de una excursión por la cuarta dimensión espacial o quinta espaciotemporal.

Concretamente, para Valle, es esta capacidad especular la que torna mágico a su esperpento: «Los héroes clásicos reflejados en los espejos cóncavos dan el Esperpento. El sentido trágico de la vida española sólo puede darse con una estética sistemáticamente deformada». ${ }^{9}$ Mientras que para Oteiza: «Hay auténtico Disparate creador [...] [cuando] lo plural entra en la cosa nueva del arte, que así aparece deformada (con-formada) en la dimensión de lo perdurable»; ${ }^{10}$ pues: «Esta actitud [...] tendría como planteo fundamental el de la conversión del plano en convexidad». ${ }^{11}$

La estética de Valle está sujeta a la segura inversión que producen los espejos: «La deformación deja de serlo cuando está sujeta a una matemática perfecta. Mi estética es transformar con matemática de espejo cóncavo las normas clásicas». ${ }^{12}$ Sin embargo, en la de Oteiza la inversión también se produce por medio de otras herramientas:

¿Mi quinta dimensión plástica? [...] (Frente a la Red de Euclides tendríamos la Red de Möebius). Frente a la anatomía plana y homogénea del espacio armónico antiguo, la anatomía curva y heterogénea de un espacio distintamente armónico. Frente a la fisiología espiritual o la estética de un hombre encerrado en la pirámide antigua, la fisiología espacial de un hombre libertado en [...] la pirámide invertida. ${ }^{13}$

Con todo, Oteiza al final de su vida reconocerá su deuda con los espejos:

el ERROR del historiador que comienza / tarde la historia en un Neolítico que / es un muro especular refleja lo que / va pasando después no lo que / hay y pasado antes al otro lado / del espejo / / he hecho como ALICIA romperlo / e

\footnotetext{
${ }^{7}$ R. del Valle-Inclán (1960), p. 13.

${ }^{8}$ R. del Valle-Inclán (2008), p. 168.

${ }^{9}$ R. del Valle-Inclán (1008), pp. 168 y 169.

${ }^{10}$ J. Oteiza (1997), p. 18.

${ }^{11}$ J. Oteiza (1997), p.130.

${ }^{12}$ R. del Valle-Inclán (2008), p. 169.

${ }^{13}$ J. Oteiza (1997), p. 38.
} 
instalarme al otro lado en busca / del comienzo de la historia en Occidente / y la cultura con nuestra primera identidad. ${ }^{14}$

Capacidad de los espejos que va más allá de su propiedad inversiva, porque ahora también nos devuelven las imágenes del pasado, como así también le sucedió a Valle: «cuando mires tu imagen en el espejo mágico, evoca tu sombra de niño». ${ }^{15}$

\section{Sentimiento trágico y sentimiento místico}

En una de las citas anteriores Valle nos decía: «El sentido trágico de la vida española sólo puede darse con una estética sistemáticamente deformada», ${ }^{16}$ sentimiento trágico que a Oteiza no le pasó inadvertido:

Es inconcebible cómo, para la totalidad de los comentadores de Goya, su pintoresca angustia erótica puede ocultarles su desgarrada angustia existencial. Suele excepcionalmente tratarse de la liberación parcial de ese sentimiento trágico ante la muerte en los Disparates de Goya. No me interesa la liberación parcial de esa angustia sino su total solución existencial, resuelta en la maquinaria estética $[\ldots]$ del arte. ${ }^{17}$

En Oteiza influyó sobremanera la figura de Unamuno, del que asimiló muchas cosas, entre las que destaca su sentimiento trágico de la vida, que en manos del escultor se convertirá en motor de su arte. De hecho, en su primer libro nos dice: «Si en la conciencia artística [...] no descubrimos la dimensión heroica de su alma, nos faltará la fuerza espiritual motriz —el sentimiento trágico [...]». ${ }^{18}$

En este libro Oteiza vincula la Estética y la labor del artista con la del hacedor de mitos que antecede a la del religioso: «precede siempre el planteamiento estético a las sistematizaciones religiosas». ${ }^{19}$ Planteamiento estético previo que nace del sentimiento trágico, frente a la sistematización religiosa que lo hace del sentimiento místico:

La actitud del sentimiento trágico: la actitud descubridora, libre de soluciones heredadas. [Mientras que] en la hora de los sepulcros-altares y del oficialismo religioso [...] se producirá la actitud conservadora: el sentimiento místico, donde los ricos herederos irán [...] repitiendo los mitos en amaneramientos barrocos,

\footnotetext{
14 J. Oteiza (1996), p.13.

${ }^{15}$ R. del Valle-Inclán (1960), p. 38.

${ }^{16}$ R. del Valle-Inclán (1999), pp. 168 y 169.

${ }^{17}$ J. Oteiza (1997), p. 29.

${ }^{18}$ J. Oteiza (2007 a), p. 212

${ }^{19}$ J. Oteiza (2007 a), p. 143.
} 
hasta que la estatua [dé] paso a la arquitectura militar e imperialista de las altas culturas andinas» ${ }^{20}$

Esto último es importante. Primero, porque el mismo matiz diacrónico, que aleja lo místico de lo arcaico, también está en Valle:

p.68: «Los pueblos de la pampa, cuando hayan levantado sus pirámides, y sepultado en ellas sus tesoros, habrán de hacerse místicos».

p.85: «En el ciclo arcaico los ojos estuvieron ciegos para todo el conocimiento místico $[\ldots] »$.

p.90: «El arte arcaico las buscó en la eternidad de las formas, el clásico en la eternidad del amor [...], el místico en la eternidad de conciencia». ${ }^{21}$

Y después, porque en él encontramos una de las primeras diferencias entre sus respectivos aparatos estéticos: mientras en el de Oteiza el sentimiento trágico prevalece sobre el místico, en el de Valle lo místico es protagonista:

p.34: «[...] el místico que sabe amarlas [todas las cosas] descubre en ellas un enlace de armonía, una divina onda cordial: la Gracia».

p. 36: «El poeta, como el místico, ha de tener percepciones más allá del límite que marcan los sentidos, para entrever en la ficción del momento, y [...] la responsabilidad eterna».

p.91: «[...] cuando nuestra conciencia deduce un goce ajeno a toda [...] utilidad temporal, comenzamos a entrever [lo] místico [...]».

p.134: «Y cuando [...] abandoné la era, de tornada por el sendero del monte, aún me estremecía aquel conocimiento místico $[\ldots] \gg{ }^{22}$

Pero además, de la mano de lo místico, encontramos la segunda diferencia importante entre las premisas estéticas de uno y otro: el dispar valor estético que ambos otorgaban a la belleza. Así, para Valle:

p.27: «Aquella tarde aprendí que los caminos de la belleza son místicos caminos por donde $[\ldots]$ transmigrar en el Alma del Mundo».

p.85: «[...] la belleza ha sido una cifra de amor y una clave teológica, pero este vuelo místico sólo lo alcanza cuando rompe el enigma».

p.132: "Yo he querido, bajo los místicos cielos de la belleza, convertir las normas estéticas en caminos de perfección $[\ldots] \gg{ }^{23}$

Mientras que para Oteiza la belleza era algo a desterrar del ámbito estético:

${ }^{20}$ J. Oteiza (2007 a), p. 171

${ }^{21}$ R. del Valle-Inclán (1960), pp. citadas.

${ }^{22}$ R. del Valle-Inclán (1960), pp. citadas..

${ }^{23}$ R. del Valle-Inclán (1960),pp. citadas. 
Cuando en las escuelas se aprenda que toda estatua [...] es un múltiple disparate natural. Que las artes no han sido Bellas ni lo han pretendido jamás. Entonces serán retirados con silenciosa vergüenza, con muda dignidad, estos rótulos que aún dicen en todos los sitios del mundo: «Escuelas de Bellas Artes». Se escribirá con entera sencillez religiosa, este otro letrero para la reanudación artística del hombre y su reeducación espiritual: «Facultad de ciencias exactas de la salvación». $^{24}$

Palabras de Oteiza en las que reconocemos a William Blake. Las obras de Blake, Swedenborg y Oteiza participan de un mismo origen: la salvación; y más concretamente, en la de Blake y Oteiza el vínculo se estrecha aún más si atendemos al papel redentor que ambos otorgaban al arte. ${ }^{25}$ Función soteriológica del arte que ya Víctor Hugo en La leyenda de los siglos simbolizó en la figura mitológica del escultor e inventor Dédalo. ${ }^{26}$

La aparición de Víctor Hugo y Blake no es ociosa pues, como veremos, sus textos están muy presentes tanto en Oteiza como Valle.

\section{Quietismo estético y realismo inmóvil}

Si consultamos el índice del libro de Valle observamos que el bloque temático central se desarrolla bajo el revelador epígrafe de Quietismo estético, y en cuanto acudimos a las páginas donde éste se desarrolla comprobamos cómo no versa de otra cosa sino del Greco. Precisamente aquél sobre el que Oteiza hace recaer en su Goya mañana: Realismo inmóvil: El Greco, Goya, Picasso la responsabilidad de haber introducido en España la corriente acosmista medieval que, desde Juan Escoto hasta Giordano Bruno, pasando por Nicolás de Cusa, acabarán heredando los pintores españoles y, a partir de ellos, él mismo.

En una de las páginas que Valle dedica al Greco leemos:

Domenico Theotocópuli [...] sabía inquirir el gesto único [...] que sólo ha de restituirnos la muerte. En el hospital de San Juan Bautista está colgado [...] el retrato del Cardenal Tavera. [...] Domenico Theotocópuli parece ser que no había visto nunca a ese terrible místico, y $[\ldots]$ que la pintura donde le representa es una evocación hecha sobre la máscara mortuoria calcada por Alonso Berruguete. [...] la máscara donde la muerte, con un gesto imborrable, había

\footnotetext{
${ }^{24}$ Jorge Oteiza (2007 a), pp. 223 y 224.

${ }^{25}$ En el legado bibliográfico del Fondo Documental de la Fundación Oteiza se custodia el ejemplar de Borges, oral que perteneció al escultor. Éste se encuentra profusamente subrayado y anotado, pero desgraciadamente faltan las páginas en las que aparece la conferencia sobre Swedenborg, donde Borges aborda las creencias que éste y Blake desarrollaron sobre la salvación.

${ }^{26}$ Oteiza llegó a dictar una conferencia en el Nuevo Ateneo de Bilbao titulada: «Mito de Dédalo y solución existencial de la estatua».
} 
perpetuado el gesto único, debió de ser como la revelación de una estética nueva para aquel bizantino $[\ldots]{ }^{27}$

Esta aparición de la temática de la máscara en la Lámpara de Valle, del que Gómez de la Serna decía que era «la mejor máscara a pie que cruzaba la calle Alcalá», no es puntual ni aislada, sino recurrente:

p.22: «Otro día, sobre la máscara de mi rostro, al mirarme en un espejo, vi modelarse cien máscaras en una sucesión precisa [...]».

p.122: «Llevo sobre mi rostro cien máscaras de ficción que se suceden bajo el imperio mezquino de una fatalidad sin trascendencia. [...] Muchas veces me pregunto cuál entre todos los pecados es el mío, e interrogo a las máscaras del vicio». ${ }^{28}$

Pero al que no le fue ajena la cuestión de la máscara fue a Oteiza, pues le dedica más de un párrafo en su Goya:

«[...] llegamos a romper el rostro individual de las cosas, situándonos en el único camino para la reintegración superior de las cosas en el arte [...]. Es la conquista, y su ingreso, de la Máscara en una supernaturaleza $[\ldots]$ único realismo del arte». ${ }^{29}$

\section{El círculo y la circunferencia}

Otra temática común en los textos de Oteiza y Valle estriba en su respectiva recurrencia sobre lo circular; aunque en este caso, como en los anteriores, la posición adoptada por ambos también va a ser contrapuesta.

En la Lámpara de Valle la palabra más repetida es «círculo», seguida de «intuición», palabras también muy presentes en los textos del escultor. Aunque con una sutil diferencia, pues Oteiza casi nunca dirá círculo sino circunferencia; que se parecen pero no son lo mismo. El círculo es la superficie que encierra la circunferencia, mientras ésta es el perímetro de aquél; el círculo es un área y la circunferencia una longitud. Pues bien, esta diferencia encierra otra divergencia entre ambas teorías estéticas.

Así, no es difícil encontrar en la Lámpara frases en las que la palabra «círculo» vaya acompañada de la de «centro»:

p.59: «[...] porque toda acción de belleza es un centro de amor que engendra los infinitos círculos de la esfera».

\footnotetext{
${ }^{27}$ R. del Valle-Inclán (1960), p. 121.

${ }^{28}$ R. del Valle-Inclán (1960), pp. citadas.

${ }^{29}$ J. Oteiza (1997), p.18.
} 
p.136: «Toda expresión suprema de arte se resume en una palpitación [...] que engendra infinitos círculos, es un centro y $[\ldots]$ quietud $[\ldots] »$.

p.143: «El arco del círculo basta para deducir el centro, y deducido el centro, el círculo está cerrado $[\ldots] \gg{ }^{30}$

O la palabra centro disociada ya del círculo al que se refiere:

p.60: «Ser bello es hacerse centro de amor $[\ldots] »$.

p.70: «Y el Arte es nuncio de aquel divino conocimiento [...] de quietud y un imán de centro, plenarios de vida, de verdad y de luz».

p.102: «[...] el alma que sabe hacerse quieta se convierte en centro, $[\ldots]$ en la relación con ella, todo queda polarizado e inmóvil».

p.137: «El centro es la unidad, y la unidad es la sagrada simiente del Todo. El centro, como unidad [...] de la esfera, y [...] se desenvuelve en la expresión geométrica inmutable $[\ldots] »$.

p.146: «Hermano, $[\ldots]$ aprende a ser centro y alma solitaria $[\ldots] »$.

p.147: «Aquellos que buscan la iniciación gnóstica se consumen en un anhelo por ser centros encendidos de amor $[\ldots] \gg .{ }^{31}$

Sin embargo, Oteiza se decanta por la circunferencia a la que indirectamente dedica sus Ejercicios espirituales en un túnel: "Al invierno / [...] el invierno es una circunferencia». Además, le dedica un apartado de dicho libro bajo el epígrafe «Alma vasca y circunferencia», en el que podemos leer: «[...] el alma de los vascos $[\ldots]$ es una circunferencia $[\ldots] »$.

Conforme uno va leyendo los escritos de Oteiza de forma cronológica y según se aproxima a su conclusión escultórica, puede que le sorprenda la multitud de elementos, como el panteísmo acosmista o la circularidad, que se encuentran en consonancia con algunas tradiciones orientales como el Budismo Zen y que, sin embargo, no se ven confirmados en ningún momento por sus palabras, porque nunca menciona dichas tradiciones hasta su Quousque Tandem...!. Y para cuando lo hace es para marcar distancias con respecto a ellas. En cierto sentido es como si tomara todos estos elementos o símbolos parejos entre sus conclusiones y las tradiciones orientales, y les diera la vuelta, generando así una suerte de orientalismo invertido, para luego proyectarlo y atribuírselo a los hombres de cromañón, que él supone ya vascos.

\section{Las menciones de Oteiza a Valle-Inclán}

Los textos de Oteiza se encuentran jalonados por multitud de referencias explícitas a otros autores; sin embargo, aunque su obra escrita es deudora en más de un aspecto de la de Valle, no abundan las menciones directas a éste, de hecho son

\footnotetext{
${ }^{30}$ R. Valle-Inclán (1960), pp. citadas.

${ }^{31}$ R. del Valle-Inclán (1960), pp. citadas.
} 
sólo dos. La primera y tangencial, la encontramos en el artículo «Grandeza y miseria de Zuloaga», ${ }^{32}$ donde dice: «[Zuloaga] pintó su famoso cuadro Mis amigos, pero para Belmonte, Valle Inclán, Baroja y Ortega, no sé hasta qué punto lo fue él» $;{ }^{33}$ y la segunda y medidamente injusta, en sus Ejercicios espirituales, donde dice: «Para llegar a la gran pintura española hay que esperar a Valle Inclán (su estilo verbal, frente al visual de Baroja $[\ldots]) »{ }^{34}$

Cita que además de ser la única en la que Oteiza se posiciona ante la obra de Valle, nos presenta uno de los muchos préstamos que aquel tomará de éste: la dualidad entre el pensamiento verbal y el visual. Dualidad que es asimétrica, como no podía ser menos en dos artistas influenciados por un panteísmo tan marcadamente acosmista.

\section{Lo verbal y lo visual}

En la segunda edición del libro de Oteiza Quousque Tandem...!, que data de 1971, el escultor introduce una serie de anotaciones manuscritas al texto original. En una de ellas subraya la siguiente frase: «Cuando se pasa del espacio al tiempo» $;{ }^{35} \mathrm{e}$ introduce debajo la siguiente correspondencia:

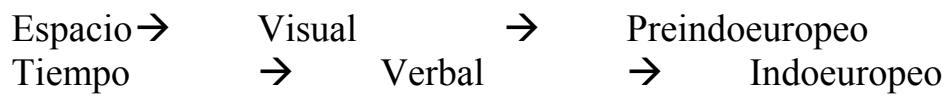

Dualidad en la que Oteiza, dada su formación escultórica donde lo espacial prevalece sobre lo verbal, se decanta por el espacio y lo visual; y dado su romántico nacionalismo, por el preindoeuropeo. Esta asimetría irá cobrando fuerza a partir de entonces. Así, en textos posteriores podemos leer frases en las que abunda en lo anterior:

Nosotros los vascos debemos considerar en dos vertientes de nuestra tradición: la consciente reciente y latina, esto es la reflexiva y verbal (lo que de verbal nos ha quedado de nuestra lengua) y la otra, la visual y que corresponde simbólicamente a nuestra primera intimidad (la intimidad estética y visual que hemos olvidado de nuestra lengua). ${ }^{36}$

\footnotetext{
${ }^{32}$ Publicado en la Revista América de Bogotá el mes y año en el que Oteiza pronunció la primera de las dos conferencias que recoge su Goya.

${ }^{33}$ J. Oteiza (2007 b), p.258.

${ }^{34}$ J. Oteiza (1984), p. 373.

35 J. Oteiza (2007 b), p.137.

${ }^{36}$ J. Oteiza (1995), p.58.
} 
Y es precisamente esta misma alternancia que nos plantea Oteiza, entre una arcaica mentalidad visual y una sobrevenida mentalidad verbal de origen latino, la que también establece Valle del siguiente modo:

p.62: «Todas las cosas bellas y mortales que nosotros creamos son para los ojos o son para los oídos, alternativamente».

p.63: «[Los primitivos griegos] tenían los ojos soberanos de las águilas y todas sus intuiciones las arrancaron a la celeste entraña del Sol».

p.64: «[...] no recibían el conocimiento del mundo como una herencia fría en la urna de las palabras, manera de entender siempre larga, oscura, cronológica y crasa. Para aquellos pastores las ideas significaban números y formas bajo el ritmo del. Sol. [...] Fue después, bajo el cielo latino, cuando los poetas, guiados por el hilo de las palabras, [...] quisieron revelar el secreto de un mundo que no sabían ver. Nació entonces [...] el remedo clásico».

p.114: «[...] mis intuiciones, me ayuda[n] para este logro, y todas las imágenes $[\ldots]$ en los ojos, $[\ldots]$ a modo de creaciones innatas» ${ }^{37}$

Como vemos Valle asocia lo visual no sólo con el sustrato ctónico preindoeuropeo de los griegos, sino también con lo intuitivo, lo innato, lo celeste y sobre todo con el Sol. Así como al asociar el sentido cronológico del hilo de las palabras con lo verbal, acaba por vincular por oposición lo visual con lo espacial. Relaciones también presentes en los textos de Oteiza: «El espacio es físico y solar, el tiempo es nocturno y metafísico». ${ }^{38}$

\section{El andrógino o la tercera raza espiritual}

En la Lámpara es fácil encontrar referencias indirectas al andrógino:

p.81,82: «Estas dos columnas representaban en la doctrina oculta de los magos [...] los misterios del antagonismo [...] entre el hombre y la mujer, porque, según la interpretación hermética, la mujer debe resistir al hombre y el hombre debe [...] someterla. El principio de acción busca al principio de negación [...]». p.85: «Apolo y Venus representan el ansia religiosa del instinto genitor por hacer divino el ideal humano».

p.88: «Lo ingrávido se enlaza con la sustancia grávida en una divina armonía de contrarios». ${ }^{39}$

Y algunas otras mucho más directas:

\footnotetext{
${ }^{37}$ R. del Valle-Inclán (1960), pp. citadas.

${ }^{38}$ J. Oteiza (1984), p .416.

${ }^{39}$ R. del Valle-Inclán (1960), pp. citadas.
} 
p.87: «En el segundo círculo se abre la rosa [...] de maravillosa geometría, rosa andrógina, $[\ldots]$ que junta en $[\ldots]$ síntesis el antagonismo [...]. Su anhelo es enlazar las formas contrarias $[\ldots] »$.

p.88: «El español y el florentino [...] expresan el mismo concepto metafísico y estético que tres mil años antes había alumbrado en el mármol andrógino de Venus Afrodita. El griego enlaza las formas contrarias. [...] armonía de antagonismos $[\ldots] \gg .^{40}$

Sin embargo, en los textos de Oteiza las referencias están presentes pero nunca acaban de ser del todo directas, aunque quizá una sí lo sea. Para los alquimistas la última etapa de la Gran Obra era también llamada por ellos la resurrección. En ella, los cuerpos de los opuestos — comunmente del principio masculino y el femeninoeran enterrados juntos en el fondo de la retorta; donde, tras la cocción, unían sus sustancias en una sola llamada rebis, a veces simbolizada por el andrógino y, en más de una ocasión, por el doble enterramiento del padre y el hijo, con la posterior exhumación de su doble osamenta. Lo que encierra un gran paralelismo con el siguiente comentario que hace Oteiza sobre el enterramiento de Goya en su Goya Mañana, más aún si atendemos al curioso verbo - principian- que en él usa el escultor:

Goya $[\ldots]$ no tiene tumba propia. La tiene [...] su buen amigo Goicoechea. En ella entierran a Goya y allí principian en descanso juntos estos dos amigos [...] A mí sólo me interesa destacar [...] estas palabras con que termina Elie Fauré $[\ldots]$ : «Y CUANDO ABRIERON EL FÉRETRO [...], HALLARON EN ÉL DOS ESQUELETOS». ${ }^{41}$

El andrógino dentro de la simbología alquímica puede ser encarnado por otras figuras procedentes de diversas religiones o mitologías, como por ejemplo la del hermafrodita. ${ }^{42}$ Con todo, la equivalencia de estas dos últimas figuras es discutible, ya que el hermafrodita es una figura de la mitología griega y el andrógino una figura a la que alude Platón en su Banquete. Allí, recordemos, se nos narra cómo la humanidad en sus orígenes se componía de tres tipos de seres dobles: los doblemente masculinos, los doblemente femeninos y los andróginos. La vanidad de estos últimos les acarreó como castigo divino su partición en dos mitades. A partir

\footnotetext{
${ }^{40}$ R. del Valle-Inclán, pp. señaladas.

${ }^{41}$ Jorge Oteiza (1997), p. 138.

${ }^{42}$ También puede representase en el momento previo a su unión por un par de figuras, por ejemplo Adan y Eva o Epimeteo y Pandora. Parejas mitológicas que es habitual que se entremezclen, con no poca confusión. Para William Blake el Adán celeste es andrógino, pero tras su descenso al mundo terrenal su parte femenina se ve disociada de la masculina. No obstante, esta disociación también encierra su salvación conjunta: les bastará con volverse a unir en forma de rebis, hermafrodita o andrógino.
} 
de ese momento, la orfandad que conlleva su nueva condición se traducirá en un impulso irrefrenable para volver a unirse. ${ }^{43}$

Esta nueva triple humanidad es fácilmente reconocible en la descripción que nos hace Oteiza de las tres razas espirituales que componen el alma de los pueblos. Según Oteiza existen tres razas y a las dos primeras les bastaría con reencontrarse la una con la otra para poder alcanzar la doble condición de la tercera: la de Goya:

Definimos como alma de un pueblo lo constante en su actitud involuntaria para obrar, su raza espiritual. Pero ¿existen pueblos de una sola raza espiritual $[\ldots]$ ? Consideremos antes cuántas [...] son las razas espiritualmente elementales (como los elementos químicos) [...]. Los cuerpos espirituales racialmente simples, son [...] 3: 1) Las razas mágicas; 2) Las razas apolíneas; 3) Las razas dionisíacas. [...] Ahora añadimos: Las combinaciones [...] son tan diversas como los pueblos [...]. Todo pueblo prehistórico victorioso, [...] lo es mágicamente, esto es, por una poderosa intuición de síntesis entre lo apolíneo [...] y lo dionisiaco [...]. Un alma apolínea para alcanzar lo mágico pasa por lo dionisiaco. Y una dionisíaca se apoya en lo apolíneo, para [...] alcanzar la victoria espiritual del Arte. ${ }^{44}$

Raza espiritual de los pueblos primitivos que, según Valle, estaba abocada a verse si no superada por lo menos suplantada:

p.52: «El espíritu primitivo — pastoril, guerrero o mitológico- deja de animarlas, nace otro espíritu en ellas y abre círculos distintos».

p.54: «En la imitación del siglo que llaman de oro, nuestro romance castellano dejó de ser como una lámpara en donde ardía y alumbraba el alma de la raza $[\ldots] \gg{ }^{45}$

Sobre este tema, en el caso de Oteiza, podríamos pensar que su teoría racial se restringe al ámbito meramente cultural o espiritual, y que por lo tanto nos encontramos ante una de tantas teorías acientíficas que arbitraria o desafortunadamente confunden los términos cultura, espíritu o alma con el de raza - como así lo parece en el caso de Valle-. Pero por desgracia no es así, pues Oteiza sí aspirará a cimentar científicamente su teoría, como lo demuestra más de una página de su Quousque Tandem...!:

No tendría sentido mi tesis [...] si el pueblo vasco actual no fuese su continuidad como grupo étnico. [...] Del volumen que acaba de aparecer $[\ldots]$ («La raza

\footnotetext{
${ }^{43}$ R. Martin (2004), p. 296.

44 J. Oteiza (1997), p. 136.

${ }^{45}$ R. del Valle-Inclán (1960), pp. citadas.
} 
vasca»), anoto $[\ldots]:$ «[...] La raza vasca es una raza típica rica en elementos $O$, luego muy pura $[\ldots] »{ }^{46}$

El tema trasciende ampliamente el objetivo de este artículo, ${ }^{47}$ sin embargo sí es importante tener presente que en este punto tanto Oteiza como Valle están haciendo uso de una errónea interpretación de la teoría de la evolución de las especies, muy en boga a finales del siglo XIX y principios del XX, la que hicieron las teologías procesales o evolutivas. Concretamente ambos están atribuyendo a dicha teoría un carácter teleológico del que en realidad carece. Aunque en esta cuestión ambos, a diferencia de las teologías procesales, están siendo decididamente involucionistas o decadentistas, al defender que las razas primigenias son superiores a las derivadas de ellas. En palabras de Oteiza:

p.79: «Ahora vais a [...] distinguir 2 tipos de mentalidad espiritual, 2 razas culturales, la nuestra, ética, en tradición prehistórica [...], y la latina, de una tradición occidental limitada por un positivismo lógico exclusivamente racionalista».

p.144: «El par polar de conceptos, que pueden hacer girar [...] nuestra actividad política actual: este separatismo [...], y este racismo espiritualista que nos conviene $[\ldots]$ como primer alma europea $»{ }^{48}$

$\mathrm{Y}$ en las de Valle:

«La mengua de nuestra raza se advierte [...] al escuchar la plática de aquellos que rigen el carro y pasan coronados al son de los himnos. Su lenguaje es una baja contaminación: francés mundano, inglés de circo y español de jácara. El romance severo, altivo, grave, sentencioso, sonoro, no está [...] en el corazón de donde fluyen las leyes. [...] La entereza y castidad mental del vasco se advierte en los sones de su lengua $[\ldots] \gg{ }^{49}$

Por otro lado, vemos también cómo el concepto de raza se encuentra en Valle entremezclado con el del lenguaje y de ahí con el relativismo lingüístico. Pero antes de abordar este debate, al que Valle desde su Lámpara maravillosa: ejercicios espirituales y Oteiza desde sus Ejercicios espirituales en un túnel dedican más de

\footnotetext{
${ }^{46}$ J. Oteiza, Jorge (2007 b), pp. 374 y 375.

${ }^{47}$ El término raza, sin necesidad de extrapolarlo a ámbitos ajenos al biológico, ya presenta multitud de problemas: la inestabilidad inherente al grupo infraespecie que designa, encontrarse totalmente superado como método taxonómico por la genética numérica... Estos problemas han derivado en una pérdida de su relevancia como término científico.

${ }^{48}$ J. Oteiza (1984), pp. citadas.

${ }^{49}$ R. del Valle-Inclán (1960), p. 50.
} 
un apartado, conviene que no pasemos por alto una última cuestión relacionada con el andrógino.

\section{El cielo y el mar}

En los textos de Oteiza, así como en la Lámpara, se nos plantea un diálogo entre el cielo y la tierra que en realidad está íntimamente ligado con el juego de espejos que siempre lleva aparejado todo panteísmo acosmista; donde todo es Dios — panteísmo-, pero la realidad no tanto - acosmista—, pues ésta no es más que un reflejo emanado de la verdadera realidad celeste. En palabras de Valle:

p.69: «Nuestros sentidos [...] son gusanos de luz sobre el [...] sendero por donde la humana conciencia transmigra en las cosas, y está en ellas como la imagen en el fondo del espejo $[\ldots] »$.

p.99: « [...] la vida es un espejo».

p.125: «Emanaba $[\ldots]$ de $[\ldots]$ los espejos mágicos».

p.135: «Alma mía, para estar en todas las cosas como la imagen en el fondo del espejo, $[\ldots]$ ama tu cárcel $[\ldots] \gg{ }^{50}$

Juego de espejos que tiene su reflejo en el diálogo que ambos escritores establecen entre cada uno de ellos y el cielo o el mar. Así, es reveladora la manera en que Valle evoca el surgir de su vocación artística:

Yo [...] transmigraba amorosamente en la conciencia de las cosas y rompía las Normas. Mis ojos y mis oídos creaban la Eternidad. Esta gracia intuitiva la disfruté por primera vez [...] mirando al mar azul. ${ }^{51}$

Oteiza también referirá cómo surgió en él su vocación en una de sus Cartas al príncipe, en la titulada El estrabismo estructural del artista vasco; que además está íntimamente relacionada con la figura del andrógino, pues en ella vuelve a incidir sobre la doble alma de Goya:

Txillida ha contado que mirando en su infancia la mar nace como escultor. Yo había contado que nací en mi infancia a la escultura mirando el cielo. Estas 2 miradas en distinta dirección y que [...] se conjugan en [...] nuestra estructura $[\ldots]$ como ESTRABISMO MENTAL $[\ldots]^{52}$

No obstante, la relación de Oteiza con el cielo y el mar también va a participar en algún momento de la mirada de Chillida/Valle. De hecho, se va a producir un diálogo entre el cielo y la tierra acompasado en tres fases sucesivas. Una primera,

\footnotetext{
${ }^{50}$ R. del Valle-Inclán (1960), pp. citadas.

${ }^{51}$ R. del Valle-Inclán (1960), p.30.

52 J. Oteiza (1988 a), p. 22.
} 
de niño, en la que enterrado en la tierra contempla y se evade mirando el cielo. Una segunda, de adulto, en la que tras haber conseguido ascender, gracias a su labor escultórica, por encima del acontecer terrenal, vuelve la vista atrás y contempla desde fuera a la Tierra como un objeto que refleja el cosmos, que contiene como infinito actual lo que desde dentro parecía un infinito potencial. Y finalmente una tercera fase en la que el anciano Oteiza volverá a mirar al cielo con ojos de niño, carácter celeste totalmente explicito en sus Nociones para una filología.

Además la mirada de Oteiza y Valle acaba por derivar en una síntesis. Mientras para Valle «e1 sentir de los griegos fue hijo del mar y del cielo [...]», ${ }^{53}$ para Oteiza la figura alquímica del Huevo filosofal se convierte en el «HUEVO VACÍO / símbolo arquetipo cosmogónico / la tierra atada al cielo». ${ }^{54}$

Y una síntesis sin fusión, en la que se respeta la alteridad de los polos. Concretamente, mientras para Valle «cada [...] [alma estética] es un pentáculo que sella la maravillosa diversidad del Todo»; ${ }^{55}$ para Oteiza «hay auténtico Disparate creador $[. .$.$] [cuando] lo plural entra en [\ldots]$ el arte». ${ }^{56}$

\section{Relativismo lingüístico}

En la Lámpara hay un momento en que el concepto de raza se empieza a entremezclar con una suerte de proto-relativismo lingüístico. ${ }^{57}$

Oteiza, por su parte, también dedica al relativismo lingüístico un apartado de sus Ejercicios, en el que nos dice: «El lingüista sabe que las palabras conservan el reflejo de las cosas que designan y del medio cultural que las emplea» $;^{58}$ o como diría Valle: «son las palabras espejos mágicos donde se evocan todas las imágenes del mundo». ${ }^{59}$

Oteiza, al abordar la relación lengua/raza, parece concluir que lengua y raza están estructuralmente imbricadas:

Txillardegui identifica idioma y forma de pensar: discuto esa identificación [...] El alma de un pueblo no es creado por el idioma, es creado con el idioma: no es un hecho, son $2,[\ldots]$ estructuralmente tenemos que diferenciar las partes $[\ldots]$ porque sin partes no hay un todo [...] y, estructuralmente, nunca lo que es una parte puede ser el todo. ${ }^{60}$

\footnotetext{
${ }^{53}$ R. del Valle-Inclán (1960), p.63.

54 J. Oteiza (1996), p. 32.

${ }^{55}$ R. del Valle-Inclán (1960), pp. 147 y 148.

56 J. Oteiza (1997), p. 18.

${ }^{57}$ La hipótesis Sapir-Whorf, además de una totalmente errada interpretación de la teoría de la relatividad de Einstein - $\mathrm{o}$, mejor dicho, Poincaré-, es posterior.

58 J. Oteiza (1984), p. 23.

${ }^{59}$ R. del Valle-Inclán (1960), p.66.

${ }^{60}$ J. Oteiza (1984), p. 408.
} 
Mientras Valle concluye que es el lenguaje el que prevalece sobre la raza:

p.51: «Toda mudanza [...] en los idiomas es una mudanza en las conciencias, y el alma colectiva $[\ldots]$ una creación del verbo más que de la raza. Las palabras imponen normas al pensamiento [...]. Los idiomas nos hacen [...]». p.49: «Cada lengua contiene el pasado de su gente $[\ldots] »{ }^{61}$

Sin embargo, si les seguimos leyendo, resulta que ambos acaban por coincidir: la lengua para los dos es dinámica, inestable y, finalmente, superable. Y es que, en último término, lo que para ambos prevalece es la raza. En palabras de Oteiza:

El vascuence ya no está en el vascuence, sino en la mentalidad del vasco, del vasco que vive mentalmente lo que el idioma le ha proporcionado, su propio ser, su propia conciencia personal. El vascuence son los restos de una herramienta [que] por si misma, hoy ya no sirve [...]. Es inútil que tratemos de colocarnos el cráneo de un antepasado para heredar sus ideas. Solamente hay un hombre vivo donde hay un arte muerto. ${ }^{62}$

$\mathrm{Y}$ en las de Valle:

«Los idiomas nos hacen, y nosotros hemos de deshacerlos. Triste destino el de aquellas razas enterradas en el castillo hermético de sus viejas lenguas [...]. ¡Y más triste el destino de vuestros nietos, si en lo por venir no engendran dialectos suyos $[\ldots] !{ }^{63}$

\section{El vacío expresivo}

Las preocupaciones de ambos sobre el lenguaje no se terminan con lo anterior, pues ambos desarrollaron una teoría sobre el mismo muy parecida a la elaborada por Wittgenstein en su Tractatus, y sobre todo al aserto que lo cerraba: «De lo que no se puede hablar hay que callar». ${ }^{64}$ Ambos desarrollaron una teoría sobre lo inefable, la afasia, la elipsis o el vacío expresivo como el mejor camino para la correcta presentación - que no representación- de lo sagrado. Una teoría que además en el caso de la Lámpara de Valle (1916) es anterior al Tractatus Wittgenstein (1918-21).

Valle nos dice desde su Lámpara: «lo que no está en nosotros larvado o consciente, jamás nos lo darán palabras ajenas»; ${ }^{65}$ palabras que recuerdan a aquellas con las que Wittgenstein abría su Tractatus: «Posiblemente sólo entienda este libro

${ }^{61}$ R. del Valle-Inclán (1960), pp. citadas.

62 J. Oteiza (1984), pp. 107 y 108.

${ }^{63}$ R. Valle-Inclán (1960), p. 52.

${ }^{64}$ L. Wittgenstein (2009), p. 132.

${ }^{65}$ R. del Valle-Inclán (1960), p.40. 
quien ya haya pensado alguna vez por sí mismo los pensamientos que en él se expresan». ${ }^{66}$ Frase que Oteiza parafraseará diciendo: «el libro, sí debe ser claro, pero claro para el que lo escribe. Es la única forma de que resulte claro y digno para el que lo lee». ${ }^{67}$

Pero esto no deja de ser anecdótico en comparación con lo que ahora veremos. Así, en el libro de Valle se pueden leer frases del tipo:

p.40: «Las palabras son $[\ldots]$ ánforas de barro, contienen la experiencia $[\ldots]$ de los afanes [...], nunca lo inefable de las alusiones eternas».

p.50: «Los idiomas son hijos del arado. De los surcos de la siembra vuelan las palabras con gracia $[\ldots] \gg{ }^{68}$

Y en los Ejercicios de Oteiza:

p.107: «Unamuno proponía al vasco el abandono de su idioma, pero argumentaba mal. El único argumento lógico es el reconocimiento de que el [...] vascuence es cóncavo y [...] solamente los idiomas cóncavos pueden dejarse [...].Todos los idiomas tendrán antes que hacerse cóncavos, que reflejar al hombre entero $[\ldots] \gg$.

p.22: «Las palabras que nos faltan son las que, como expresión de lo sagrado, se ocultan. [...] dejan su sitio vacío en nuestro idioma»

p.102: «[...] las palabras son señales llenas de significado para los demás. Pero esto es en la primera fase $[\ldots]$. En nuestra tradición hay una segunda fase, $[\ldots]$ en la que las palabras pueden irse $[\ldots]$ vaciando $[\ldots]$ hacia la trascendencia de su sentido. [...] La palabra misma, al crecer en su interior el silencio que la ajusta a la expresión espiritual de lo sagrado, puede [...] ser retirada voluntariamente, dejando $[\ldots]$ un sitio vacío».

p.103: «Si no tenemos, por ejemplo, la palabra Dios [...], nos puede haber sucedido lo que a los judíos, que teniéndola (Jehová, Yahvé) no se atreven por sagrada a pronunciarla $[\ldots] »$

p.104: «Nuestra cortedad en palabras la podemos entender como la extensión al lenguaje de una fe activa en el silencio para las palabras sagradas $[\ldots ..] \gg{ }^{69}$

Frases donde podemos reconocer la teoría que elaboró Valle sobre el silencio como única vía expresiva para lo inefable:

p.24: «QQué mezquino, qué torpe, qué difícil balbuceo el nuestro para expresar este deleite de lo inefable que reposa en todas las cosas con la gracia de un niño

\footnotetext{
${ }^{66}$ L. Wittgenstein (2009), p.47.

${ }^{67}$ J. Oteiza (2007 a), p. 158.

${ }^{68}$ R. del Valle-Inclán (1960), pp. citadas.

${ }^{69}$ J. Oteiza (1984), pp. citadas.
} 
dormido! [...] Hay algo que será eternamente hermético e imposible para las palabras»».

p.23: «El poeta solamente tiene algo suyo que revelar a los otros cuando la palabra es impotente para la expresión $[\ldots] \gg .^{70}$

Podríamos conjeturar que en el caso de Oteiza este aspecto de su teoría deriva de la influencia del Tractatus Wittgenstein, antes que de Valle. De hecho, en su Fundación se custodia un mecanoescrito del escultor en el que comenta su lectura del Tractatus, y en especial hace la siguiente acotación a la famosa máxima con la que Wittgenstein cierra su libro:

Pero terminaremos de hablar y también concluiremos en este silencio idéntico. Como escultor no he precisado hablar más desde 1958. Lo que ahora estoy intentando explicar está $[\ldots]$ condenado al mismo silencio. Hablo precisamente para explicar este silencio, para crear este silencio.

Muchos asertos del Tractatus se encuentran en sintonía con lo arriba expuesto por Oteiza y Valle: «No es lo místico como sea el mundo, sino que sea el mundo. [...] Hay en verdad cosas que no se pueden poner en palabras. Se manifiestan. Son lo místico». O como diría Oteiza: «Una obra de arte puede ser un estímulo no asociado, no ser un signo sino un objeto, no una representación de la realidad sino una realidad». ${ }^{71}$ Sin embargo, la influencia de Wittgenstein en Oteiza es muy tardía, no así la de Valle.

\section{El vacío resonante}

En el apéndice documental de sus Ejercicios Oteiza anexa una serie de cartas dirigidas al Obispo de San Sebastián. En ellas comenta las vicisitudes que acompañaron la conclusión del friso de Aranzazu. En ellas el escultor, que ya había concluido su labor escultórica años antes tras vaciar de tal manera sus esculturas que se quedó sin ella en la mano, propone al Obispo la terminación del friso en forma de vacío resonante:

Si todo ha desaparecido la conclusión final vacía [es] válida como pura receptividad. Pero $[\ldots]$ este vacío, será siempre una resonancia $[\ldots]$ del estado anterior. [...] La consistencia de la conclusión vacía, equivaldría [...] a la creación de $[\ldots]$ una resonancia de Dios. [...] he procedido en mi Ley bifásica [...] para la expresión, pasando de una ley física a una metafísica, [...] hasta la imagen por resonancia, de Dios, en un vacío. Y [...] pienso en [que] Dios creó la Luz: quizá este Vacío resonante, esta luz espiritual, sea la estructura íntima de la

\footnotetext{
${ }^{70}$ R. del Valle-Inclán (1960), pp. citadas.

${ }^{71}$ Jorge Oteiza (2007 a), p. 132.
} 
Materia, del Universo. [...] En este sentido [...] el Friso se borraría en una resonancia vacía. ${ }^{72}$

Resonancias también presentes en Valle:

p.99: «Bajo sus arcos poblados de resonancias se experimenta el vértigo como ante los abismos $[\ldots]$ de la Teología».

p.104: «[...] sus hastiales [...] tienen las evocaciones de una crónica que en bárbaro latín reza loores de santos [...], pero su ámbito sin resonancias nunca es bello $[\ldots] \gg$.

p.104-105: «Compostela $[\ldots]$ junta $[\ldots]$ en una sola evocación $[\ldots]$ ecos [de] la misma resonancia».

p.126: «El alma de la ciega era como un caracol marino lleno de resonancias, $[\ldots]$ llena del rumor de los maizales $[\ldots] »$.

p.143: «El dolor del pecado agranda el ámbito de nuestra ciudad interior, y lo llena de resonancias infinitas». ${ }^{73}$

\section{La mónada o la panóptica simiente}

Pero quizá el mayor paralelismo encontrado entre las teorías estéticas de ambos autores, venga de la mano de aquella famosa poesía de William Blake que decía: «Para ver el mundo en un grano de arena / y el Cielo en una flor silvestre / abarca el infinito en la palma de tu mano / y la eternidad en una hora».

En ella, el poeta ingles se hizo eco de la teoría que sobre las mónadas elaboró en su día Giordano Bruno, filósofo napolitano al que Oteiza dedica un apartado en su Goya mañana, y al que Valle se refiere indirectamente cuando dice: «que los caminos de la belleza son místicos caminos por donde [...] transmigrar en el Alma del Mundo» $;{ }^{74}$ expresión con la que Bruno en su Expulsión de la bestia triunfante define a Dios: «si Dios no es la Naturaleza per se, sin duda es la naturaleza de la Naturaleza: es el alma del Alma del Mundo». ${ }^{75}$

Pero ahora Bruno nos interesa por los dos poemas que publicó nueve años antes de ser quemado en la hoguera: Del triple mínimo, De la mónada. ${ }^{76}$ En el primero Bruno define los átomos del mismo modo que ya lo hicieran Demócrito y Lucrecia: como semillas capaces de contener dentro de sí el universo en potencia. De ahí la importancia de las siguientes frases de Valle:

p.34: «El conocimiento de un grano de trigo [...] nos daría el conocimiento pleno del Universo».

\footnotetext{
72 J. Oteiza (1984), pp. 152 y 153.

${ }^{73}$ R. del Valle-Inclán (1960), pp. citadas.

${ }^{74}$ R. del Valle-Inclán (1960), pp. 27 y 28.

${ }^{75}$ I. D. Rowland (2010), p. 197.

${ }^{76}$ I. D. Rowland (2010), p. 252.
} 
p.134: «Yo estaba en la era $[\ldots]$ y el viejo [...] me trajo un puñado de trigo, que [...] trasegó en la palma de mi mano [...] La vía sacra del mundo se abría para mí, y me colmó el alma [...] aquel puñado de fruto [...] en la palma de mi mano, tan mística intuición [...] que cada grano se me reveló distinto con otra promesa de simiente [...], la mirada inefable, la visión gnóstica que aún pide a mi ciencia [...] expresión distinta por cada grano».

p.137: «La unidad es la sagrada simiente del Todo». ${ }^{77}$

En el segundo tratado, De la mónada, Bruno, partiendo de la Monas hieroglyphica de John Dee que representaba la totalidad del ser, tanto macroscópica como microscópica, dota a sus átomos/semillas de la capacidad de evocar en su infinita pequeñez puntual la inabarcable infinitud potencial del cosmos: «El orden de una figura en particular y la armonía de un número particular evocan todas las cosas». ${ }^{78}$ El infinito de la totalidad encerrado en una figura, o como diría Valle: «El infinito y la unidad son modos del quietismo matemático [...]». ${ }^{79}$

Pero en este caso la visión de la mónada que más nos interesa es la que dio Leibniz, tras leer a Bruno, en su Monadología, y según la cual cada mónada refleja el Universo. Reflejo del infinito que sólo se hace visible como unidad cuando se lo observa desde fuera y desde cierta altura; en palabras de Valle: «fui lobo en un monte de ovejas, y el divino reflejo de la Idea Única se abrió en un haz de ideas menores». ${ }^{80}$

Desde ese privilegiado punto de vista el observador logra la visión panóptica a la que se refiere Valle del siguiente modo:

p.15: «Pero cuando nuestra voluntad se reparte para amar a cada criatura separadamente y en sí, jamás asciende de las veredas meditativas a la cima donde la visión es una suma».

p.101: «El recuerdo es la alquimia que depura todas las imágenes y hace de nuestra emoción el centro de un círculo, igual al ojo del pájaro en la visión de altura».

p.112: «Sólo en la suma de todas las miradas puede engendrarse la ideal mirada fuera del Tiempo».

p.115: "Cada mirada apenas tiende un camino de conocimiento a través de la esfera que se cierra en torno de todas las cosas [...] esta suprema visión que aprisiona en un círculo todo cuanto mira».

p.117: «[...] si miras con todos los ojos, amarás con todos los corazones». ${ }^{81}$

${ }^{77}$ R. del Valle-Inclán (1960), pp. citadas.

${ }^{78}$ I. D. Rowland (2010), p. 623.

${ }^{79}$ R.del Valle-Inclán (1960), p.134.

${ }^{80}$ R. del Valle-Inclán (1960), p. 139.

${ }^{81}$ R. del Valle-Inclán (1960), pp. citadas. 
Mientras que Oteiza escribe en su Goya mañana:

p.39: «Sólo desde esos 3 ángulos, [...] estereoscópicamente, el producto estético [...] se nos puede ofrecer con [la] verdadera superioridad. Es el Realismo inmóvil, [...] panóptico, del Ser estético».

p.37: «Imagen aproximada de una futura cualidad mural: Los centros rectores en el exterior, donde se reanudan inmovilizándose en la nueva totalidad funcional en la que queda encerrado, panópticamente, el nuevo espectador». ${ }^{82}$

$\mathrm{Y}$ en sus Ejercicios:

El artista, en el arte, está situado en el sitio panóptico, en la zona central de convergencia, de todas las zonas de la realidad [...], y trata de un saber humano de salvación $[\ldots]^{83}$

Y por último, tanto Valle como Oteiza van a retomar otra variante del enfoque de Bruno, pues este último llevó este concepto de la mónada mas allá de su originaria naturaleza espacial, para hacerlo extensible al tiempo: «Pasado o presente, sea cual fuere el que elijas, o también el futuro: todos son un solo presente, ante Dios una unidad infinita». ${ }^{84}$ Mientras en la Lámpara podemos leer frases del tipo:

p.30: «El momento más pequeño era un sésamo que guardaba sensaciones de muchos años».

p.32: «Cuando se rompen las normas del Tiempo, el instante más pequeño se rasga como un vientre preñado de eternidad».

p.82: «Aquel que en el grano infinitamente pequeño de cada instante gozase en amor todas las vidas $[\ldots] \gg$.

p.59: «El instante más pequeño de amor es eternidad».

p.99: «[...] en el grano de polvo palpita el enigma del Tiempo».

p.132: «Es un eterno nacimiento en el grano infinitamente pequeño de todos los instantes $[\ldots] \gg$.

p.145: «Cada vida es un instante, $[\ldots]$ infinitamente pequeño $[\ldots] \gg .{ }^{85}$

En el poema que Oteiza escribió sobre el mito de Acteón —en clara referencia a Bruno- como guión para la película con la que pretendía iniciar su frustrada incursión en el cine, Yo soy Acteón, también aparecen frases de este tipo:

[...] aparece el hombre / [...] su pasado y su futuro se encuentra en ese instante / mi tiempo íntimo reversible por su atenta agilidad dentro de la cámara dispara su

${ }^{82}$ J. Oteiza (1997), pp. citadas.

83 J. Oteiza (1984), p. 45.

${ }^{84}$ I. D. Rowland (2010), p. 257.

${ }^{85}$ R. del Valle-Inclán (1960), pp. citadas. 
mirada / [...] / como un nadador vencido empujando por la corriente $[\ldots]$ respirando el agua y el aire / cuando puede en el río del tiempo sin geometría / viviendo y muriendo [...] / siempre en el instante / [...] / soy el instante de vuestra totalidad / [...] / creación es la puesta todo en el instante / [...] / para que no tengas pasado sino instante / para que no produzcas muertos de los que tengas que escaparte, para que no sigas siendo el muerto que eres que no quiere vivir. ${ }^{86}$

\section{La sombra del plagio}

La obra de Oteiza, como en menor medida la de Valle, está ensombrecida por la eterna sospecha del plagio. Ambos eran muy dados a reinventarse su historia y la de su pueblo tomando de aquí y allá lo que les convenía a cada instante. Valle, por suerte, vivió una época en la que ese tipo de trasuntos eran todavía moneda de cambio común en la labor del poeta, mientras que Oteiza no. Es más, siempre que alguien dudó públicamente de su autoría sobre alguna de sus creaciones, el escultor se defendió atacando, esto es, acusando de plagiario suyo al que le acusó. De hecho, llegó a escribir todo un libro sobre esta cuestión, El libro de los plagios, en el que tacha a Chillida como tal.

Pero por muy virulentas que fueran las reacciones con las que esperaba acallar a los que así lo acusaban, la duda nunca se desvaneció:

El problema con Oteiza -indica uno de sus antiguos colaboradores [...]- es que [...] se inspiró exageradamente en Nicholson, en Jacob Epstein y en Moore. El pasaje de Quosque Tándem...! en el que describe cómo el hombre primitivo coloca una mano sobre la roca y se descubre a sí mismo como un hombre y no como un animal está copiado literalmente de Las lágrimas de Eros, de Georges Bataille. $^{87}$

Sea así o no, lo que sí es cierto es que Oteiza termina su Goya Mañana con un curioso comentario sobre el Guernica de Picasso que el escultor añadió al final de su vida. Y es posible que si leemos este comentario sustituyendo las palabras «Picasso», Guernica, «Juan Pantoja de la Cruz» y San Agustín rodeado de religiosos, por «Oteiza», Goya Mañana, por poner uno de sus libros, «ValleInclán», y La lámpara maravillosa, respectivamente, es posible que este texto encierre toda una confesión póstuma del escultor:

Voy a hablar de influencias o correspondencias con el estilo del Guernica que yo conozco muy bien, pero de influencias como conocimiento de otras creaciones [...] que, evidentemente, ha buscado para apoyarse Picasso, pero que por su personal y genial decisión creadora, por su resultado o encuentro original, se puede comprender que Picasso diga que él no busca, que encuentra.

\footnotetext{
${ }^{86}$ J. Oteiza: «Yo soy Acteón: poema», (1988 b), pp. 232 y 234.

${ }^{87}$ J.L. Barbería: «Una visita a Oteiza» (2002), p. 80.
} 
Hay una reproducción, San Agustín rodeado de religiosos, de un pintor de Felipe II, Juan Pantoja de la Cruz, que me hace mucha gracia porque se corresponden en todo como dos hermanos gemelos, son tan distintos y exactamente son lo mismo, cuanto más los miro más los relaciono. Las mismas proporciones, la misma distribución, la misma atmósfera nocturna, se oscurecen las mismas zonas o se iluminan [...]. Sin cambiar de posición, la monja [...] extiende el brazo con su lámpara en la mano en el Guernica. ${ }^{88}$

\section{Conclusión}

La obra teórica de Oteiza se encuentra vertebrada por la misma temática que aborda Valle-Inclán en su Lámpara maravillosa, e incluso por la teoría del esperpento de sus últimas producciones.

La temática que Oteiza parece tomar de Valle en algunos puntos se encuentra severamente alterada, llegando incluso a verse invertida en alguna cuestión, pero no por ello deja de ser la misma temática.

El préstamo que Oteiza parece tomar de Valle no se encuentra reconocido en ningún escrito del guipuzcoano —-más bien al contrario-, de ahí que podamos afirmar que nos encontramos ante uno más de los muchos misterios que pueblan la Historia de la Literatura.

No hay ningún dato que avale inequívocamente el conocimiento de la Lámpara de Valle por parte de Oteiza. No obstante, tampoco hay nada que lo desmienta, y sí un aluvión de datos que apunta en esa dirección, llegando incluso a poder afirmarse que La lámpara maravillosa: ejercicios espirituales de Ramón María del ValleInclán es uno de los mejores resúmenes de las teorías estéticas de Jorge Oteiza.

\section{Obras citadas}

BARBERÍA, José Luís: «Una visita a Oteiza», El País Semanal, Madrid, n. 1329, 17/03/2002, pp. 72-80.

GRAVES, Robert: Los mitos griegos, Madrid, Alianza, 1996.

MARTIN, René: Diccionario de mitología clásica, Madrid, Espasa, 2004.

OTEIZA, Jorge: Ejercicios espirituales en un túnel, San Sebastián, Hordago,1984.

- Cartas al príncipe, Pamplona, Pamiela, 1988 a.

- «Yo soy Acteón: poema», Oteiza, Propósito experimental, Madrid, Fundación caja de pensiones, 1988 b, pp. 231-234.

- Nociones para una filología vasca de nuestro preindoeuropeo, Pamplona, Pamiela, 1996.

- Goya mañana: el realismo inmóvil: el Greco, Goya y Picasso, Alzuza, Fund.Museo J. O., 1997.

- «Mito de Dédalo y solución existencial de la estatua», Espacialato: Oteiza, catálogo sala García Castañon, Pamplona, 2000, pp. 95-112.

${ }^{88}$ Jorge Oteiza: Goya mañana, Alzuza, Fund.-Museo J. O., 1997, p. 158. 
-Interpretación estética de la estatuaria megalítica americana, Alzuza, Fund.Museo J. O., 2007 a.

- Quousque tandem...!, Alzuza, Fund.-Museo J. O., 2007 b.

RoDRÍGUEZ SALÍs, Jaime: Oteiza en Irún, Irún, Luís de Urunzu K. T., 2003.

Rowland, Ingrid D.: Giordano Bruno, Ariel, Planeta, Barcelona, 2010.

VALLE-INCLÁN, Ramón: La lámpara maravillosa, Madrid, Espasa, 1960.

- Luces de bohemia, Madrid, Espasa, 1998.

WitTGENSTEIN, Ludwig: Tractatus logico-philosophicus, Madrid, Espasa, 2009. 